* Doutorado em Direito pela Pontifícia Universidade Católica de São Paulo, Brasil (2011) Professor Adjunto da Universidade Estadual de Londrina. E-mail: brasil.ana claudiazuin@live.com

** Mestre em Direito Negocial pela Universidade Estadual de Londrina. Especialista em Direito Constitucional Contemporâneo pelo I D C C - L o n d r i n a / UNIBRASIL. Bacharel em Direito pela Universidade Estadual de Londrina. Analista Judiciário da Justiça Federal. everton_pona @ hotmail.com

\section{A perda da chance na jurisprudência do Superior Tribunal de Justiça - os (des)caminhos de uma compreensão teórica}

\author{
THE LOSS OF CHANCE ON THE SUPERIOR COURT \\ OF JUSTICE'S JURISPRUDENCE - THE \\ (MIS)DIRECTIONS OF A THEORIC COMPREHENSION
}

\author{
* Ana Cláudia Corrêa Zuin Mattos do Amaral \\ ** Everton Willian Pona
}

RESUMO: O artigo demonstra que, com a alteração da noção de dano injusto para abarcar não somente a violação de direitos subjetivos, mas também a lesão a interesses legítimos, tornouse possível a expansão da categoria de danos indenizáveis e, por consequência, permitiu-se o reconhecimento da ressarcibilidade do dano pela perda da chance. A partir desse pressuposto, baseando-se em referenciais teóricos nacionais e estrangeiros (sobretudo das doutrinas francesa e italiana), analisam-se os julgados do Superior Tribunal de Justiça que tratam da temática, resultantes da busca realizada por meio das palavras "perda" e "chance", eliminados aqueles cujo teor decisório não aborda diretamente a teoria ou a contemplam para tratar da responsabilidade civil médica. Restringe-se, portanto, a análise, aos casos denominados de aplicação clássica da teoria da responsabilidade civil pela perda da chance, nos quais há frustração de um processo aleatório cujo resultado seria uma vantagem ou o afastamento de um prejuízo, sem que jamais se tenha conhecimento de qual seria tal resultado. Essa abordagem evidencia, desse modo, como tem sido a receptividade da teoria, destacando os acertos e aparentes equívocos na compreensão e caracterização dessa nova modalidade de dano, demonstrando, ao fim, não haver univocidade dos posicionamentos externados no Superior Tribunal de Justiça, cujas decisões ora não consideram a chance perdida passível de ressarcimento; ora a reconhecem como dano autônomo mas a caracterizam como dano emergente ou lucro cessante ou, ora somente lhe atribuem a função de agregador do dano moral.

Palavras-chave: Dano; Interesse legítimo; Perda da chance; Jurisprudência; Superior Tribunal de Justiça.

Abstract: The article aims at demonstrating that, with the modification of the concept of wrongful damage in order to embrace not only the violation of subjective rights but also the 
injury caused to legitimate interests, the recognition of a new damage category, called the loss of chance, became possible. From this assumption, based on national and foreign doctrines (mainly French and Italian), it analyses the Brazilian Superior Court of Justice's decisions concerning this issue that were the result of a search realized by the words "loss" and "chance". For the purposes of the study, all decisions that the central problem was not directly concerned to the theory of loss of chance or it were related to medical liability have been eliminated from the sample. Because of that, the analysis is restricted to the decisions in which the classical loss of chance theory has been applied, meaning the cases in which there is a frustration of an aleatory process at the end of which there would be an advantage or the possibility to avoid a loss, but noboby will ever be capable of knowing the final result. This approach highlights, thus, how has been the theory acceptation in the Brazilian Superior Court of Justice and punctuates the successes and misconceptions of the comprehension and characterization of this new type of damage. Furthermore, it also demonstrates there is no concurrency in the Superior Court of Justice, whose decisions sometimes do not admit the compensation for the loss of chance; every now and then, although they recognize the loss of chance as a new type of damage, they characterize it as consequential damages or lost profits or, instead, only as aggregating the value of moral damage.

Keywords: Damage; Legitimate interest; Loss of chance; Jurisprudence; Superior Court of Justice. 


\section{INTRODUÇÃO}

As fronteiras da responsabilidade civil já não são mais as mesmas. Os estudos pautados na teoria tradicional demasiadamente relacionada com a persecução do agente causador do dano, com o foco direcionado para a constatação da culpa no caso concreto a fim de se permitir a responsabilização, cada vez mais, caminham para a obsolescência. A vanguarda civilista preocupase agora com outro paradigma, hoje centrado na busca do efetivo ressarcimento do dano injustamente suportado pela vítima.

Nessa perspectiva, demonstra-se a ocorrência de uma ampliação da categoria dos danos indenizáveis, sobretudo a partir da virada copernicana provocada pela Cassazione $\mathrm{n}^{\circ}$. 500/99, da Suprema Corte di Cassazione italiana, a qual considerou objeto de ressarcimento o dano proveniente da lesão a interesses legítimos e não apenas a direitos subjetivos, dando margem para a posterior construção do conceito de dano injusto como a violação a interesses legítimos, entendendo-se por legítimos aqueles interesses de inegável relevância para o equilíbrio da vida em sociedade e das relações intersubjetivas.

A partir dessa decisão, o horizonte dos danos ressarcíveis ampliou-se. Não somente direitos subjetivos violados passam a merecer tutela normativa e a atuação visando à reparação ou compensação do dano proveniente de sua lesão - distinguindo-se, para rigor técnico, os termos como sendo o dano patrimonial reparado e o extrapatrimonial, compensado -, mas também os interesses legítimos dos indivíduos, os quais, apesar de não albergados expressamente sob o manto do direito objetivo, quando violados, geram prejuízo injusto à vítima.

O cenário atual mostra-se propício, portanto, na toada de expansão da categoria dos danos ressarcíveis, à discussão acerca do dano pela perda da chance, cuja teoria, se ainda engatinha entre a doutrina e jurisprudência nacionais, tem construção mais sólida - mas também não menos controvertida - na doutrina e jurisprudência estrangeiras, sobretudo no direito francês e italiano, ancorada nos estudos de autores como Geneviève Viney e Patrice Jourdain, Massimo Bianca, Maurizio Bocchiola e Adriano De Cupis.

Ultrapassada a compreensão das chances frustradas como legítimos interesses violados, passíveis de ressarcimento, por meio da análise bibliográfica nacional e estrangeira, traz-se à baila a conformação doutrinária responsável pela interpretação do que se compreende juridicamente por perda da chance, rememorando antecedentes históricos do surgimento da teoria. Uma vez fixadas 
tais premissas, torna-se possível analisar os arestos do tribunal responsável por uniformizar a jurisprudência infraconstitucional no país - o Superior Tribunal de Justiça (STJ) - a respeito dessa nova seara da responsabilidade civil.

Do universo de decisões do Superior Tribunal de Justiça, realizou-se busca com os termos "perda" e "chance" o que resultou, em outubro de 2014, na relação de 42 decisões. Após a análise dos acórdãos, eliminaram-se aqueles cuja ementa, apesar de relacionar um dos termos pesquisados, não apresentavam, no inteiro teor do decisum, qualquer ligação direta com a aplicação da teoria, não desenvolvendo-a, em razão de não ser objeto da controvérsia ou por questões de natureza processual, que impediram a apreciação, pelo referido tribunal, da quaestio vexata.

Uma vez selecionados os casos nos quais a aplicação da teoria foi devidamente enfrentada, destinou-se a atenção da pesquisa para as situações de utilização da teoria clássica da responsabilidade civil pela perda da chance clássica, circunstâncias nas quais a análise do dano pela perda da chance se dá por aplicação da premissa acima estabelecida, ou seja, da expansão da categoria de danos ressarcíveis. Devido a essa limitação metodológica, não serão estudadas as decisões cujo substrato fático para a caracterização da perda da chance repouse em casos de responsabilidade civil médica (nos quais o debate volta atenção mais à causalidade - discutindo o nexo sob o enfoque da teoria da causalidade parcial - do que à expansão dos danos).

O estudo dos julgados do Superior Tribunal de Justiça empreendido neste escrito não pretende estruturar-se considerando o juiz como produtor exclusivo do direito, justamente por não olvidar da inegável força participativa das demais fontes (formais ou materiais). Do mesmo modo, não objetiva traçar abordagem fundada em uma determinada vertente hermenêutica, adentrando na importante e implexa seara da interpretação e aplicação do direito. Não se enveredou esforços nesse caminho ao tratar-se da perda da chance, questionando a correção das decisões analisadas sob o enfoque de determinado paradigma jusfilosófico.

Ao repousar as lentes nas decisões do tribunal responsável pela uniformização da jurisprudência no país, intenta-se verificar como se desenvolve o processo de assimilação uma vertente doutrinária nova e controversa. Estabelecida a premissa de compreensão da teoria e as bases consideradas adequadas, o texto aponta diversas incompreensões por parte dos julgadores o que demonstra a necessidade de diálogo de fontes (alinhando-se jurisprudência e as reflexões doutrinárias) para a correta adoção da teoria da responsabilidade civil pela perda da chance. 
Delimitado o espectro de análise, observa-se a falta de unicidade de interpretações a respeito do dano pela perda da chance no Superior Tribunal de Justiça. As diferentes compreensões conduzem a distintas formas de concessão do ressarcimento, nem sempre alinhadas à adequada compreensão teórica que edificou a perda da chance como dano ressarcível.

Extrai-se, portanto, a premente necessidade de desenvolvimento das reflexões acerca da teoria, a fim evitarem-se que prejuízos de ordem patrimonial e extrapatrimonial efetivamente suportados por vítimas de eventos danos permaneçam sem ressarcimento em razão da falta de substancial concordância jurisprudencial a respeito da caracterização do dano pela perda da chance.

\section{A EXPANSÃO DA CATEGORIA DOS DANOS INDENI- ZÁVEIS: PERDA DA CHANCE COMO LESÃO A INTERESSES LEGÍTIMOS}

A estruturação do instituto da responsabilidade civil, tradicionalmente, ancorou-se sob quatro fortes sustentáculos: conduta, dano, nexo de causalidade e culpa.

Pouco a pouco, entretanto, significativas alterações na forma de abordagem doutrinária e jurisprudencial puderam ser observadas. Isso porque, com as velozes transformações tecnológicas, as quais, por sua vez, provocam mudanças sociais e interferem na forma dos indivíduos interagirem, novas situações conflituosas pululam e clamam por solução, por restauração e reequilíbrio. A responsabilidade civil apresenta-se como uma das mais eficazes respostas do direito em relação às alterações fático-sociais que interferem nas relações interpessoais.

Quanto ao aumento das hipóteses de ressarcimento, sabe-se que a responsabilidade civil é um dos instrumentos jurídicos mais flexíveis, dotado de extrema simplicidade, estando apto a oferecer a primeira forma de tutela a interesses novos, considerados merecedores de tutela tão logo sua presença seja identificada pela consciência social, e que de outra maneira ficariam desprotegidos, porque ainda não suficientemente amadurecidos para receberem atenção e, portanto, regulamentação própria por parte do legislador ordinário (MORAES, 2010, p. 323).

Nesse cenário de mudança, no qual a culpa deixa de ser elemento central e passa-se a admitir a objetivação da responsabilidade, a noção de dano ressarcível sofreu significativo alargamento. 
A expansão das fronteiras do dano reparável ocorre com o surgimento de novos tipos de danos no sistema da responsabilidade civil, como, por exemplo, quando a jurisprudência italiana identifica a perda da chance enquanto nova modalidade de dano, com características próprias, e o direito argentino, que na atualidade, acompanhando a doutrina francesa (LE TORNEAU, 2003, p. 34), passa a acolher a relativização do dano certo, considerando que, em determinadas situações, pode ser suficiente para o cabimento da reparação uma mera possibilidade de prejuízo.

O passar de olhos apressado na dicção do art. 186, do Código Civil brasileiro, cuja redação menciona: "aquele que, por ação ou omissão voluntária, negligência ou imprudência, violar direito e causar dano a outrem, ainda que exclusivamente moral, comete ato ilícito", associado ao art. 927 do mesmo diploma, poderia conduzir à conclusão de que a referência que ali se faz é à violação a um direito subjetivo do indivíduo. Isso porque a expressão "violar direito" contida na norma remete à noção de violação a direito subjetivo, enquanto facultas agendi, definido, no aproveitamento do que de substancial extrai-se das teorias da vontade e do interesse, como sendo "o poder reconhecido pelo ordenamento a um sujeito para a realização de um interesse próprio" (PERLINGIERI, 2002, p. 120).

Nesse aspecto somente, então, como em outra oportunidade destacado, "quando a conduta violasse direito subjetivo individual, permissão legal dada pelo ordenamento, faculdade concedida pela norma para o sujeito agir dentro do círculo e na persecução de seus particulares interesses, e causasse dano, esse seria passível de reparação, haja vista a previsão legal de proteção ao direito violado" (AMARAL; PONA, 2012, p. 26).

Desde a posição externada pela Corte di Cassazione italiana na sentença $n^{\circ} .500 / 99$, a noção de dano ressarcível tem prescindido da ocorrência de lesão a um direito subjetivo. Nesse julgado, há uma alteração da compreensão que se fazia da injustiça do dano, exigida pelo art. 2043 do Código Civil Italiano, como autorizadora da ressarcibilidade do dano observado no caso concreto.

Em verdade, reconheceu-se que, em diversas ocasiões, impunha-se à vítima o ônus de suportar um prejuízo decorrente de um ato lesivo em razão de tal ato não ter afetado um direito subjetivo previsto no ordenamento, mas tão somente um interesse jurídico. A despeito de tal orientação, diz-se que a jurisprudência italiana chegava mesmo a mascarar como direito subjetivo situações que não o eram, a fim de garantir a indenização à vítima (BIANCA, 
2002, p. 978) ${ }^{1}$. Essa situação, pois, foi revertida a partir do mencionado julgamento.

A partir de então, passou a ser possível afirmar como sendo injusto e, portanto, passível de ressarcimento, segundo a doutrina italiana, "o dano causado pelo agente que, agindo culposa ou dolosamente, viole interesses juridicamente relevantes ou tutelados da vítima, pelo que deve ser responsabilizado, como decorrência da imperatividade da regra de que ninguém tem o direito de causar dano a outrem" (AMARAL; PONA, 2012, p. 30).

Entretanto, ao mesmo tempo em que proclamou a ressarcibilidade dos danos oriundos da lesão a interesses legítimos, a Corte italiana destacou que não se trata de qualquer interesse de fato o merecedor de tutela jurídica. Para fins de caracterizar um dano passível de ressarcimento faz-se necessário tratarse de interesse relevante para o ordenamento jurídico. Por isso na doutrina italiana há quem afirme que "per parlare di danno ingiusto ocorre piuttosto che siano lesi interessi giuridicamente tutelati nella vita di relazione" (BIANCA, 2002, p. 978) $)^{2}$.

O foco, pois, reside no fato de observar-se, no caso concreto, um dano injustamente suportado por um indivíduo, independentemente se a origem de tal dano é a lesão a um direito subjetivo ou interesse jurídico do sujeito.

A expressa previsão legal de um direito supostamente violado por uma conduta lesiva não mais se apresenta como condição única para a viabilidade do ressarcimento. A diversidade das situações fáticas demonstra ser irrelevante a ausência de prévio acolhimento pelo direito objetivo, de modo que, se atingidos interesses legítimos dos sujeitos envolvidos, relevantes para a vida de relação, configurado estará o dano ressarcível.

Em relação ao dano pela perda da chance, somente com esse novo enfoque as barreiras eventualmente levantadas contra a possibilidade de ressarcimento podem ser superadas. Uma pesquisa pela autorização legal para o ressarcimento das chances frustradas restaria infrutífera. Por outro lado, merece consideração o fato de que tem relevância para o ordenamento a

\footnotetext{
1 A Corte de Cassação italiana, ao afirmar na sentença $n^{\circ}$. 500/99 a tutela ressarcitória da situação subjetiva, expõe: "che del diritto soggettivo non avevano la consistenza, ma che la giurisprudenza di volta in volta elevava alla dignita di diritto soggettivo...(come nel) caso del c.d. diritto all'integrita del patrimonio". Tradução livre: que de direito subjetivo não tem consistência, mas a jurisprudência, vez ou outra, eleva-o a tal categoria, como nos casos do direito à integridade do patrimônio.

2 Tradução livre: Para falar em dano injusto, é necessário que tenham sido lesados interesses juridicamente tutelados na vida de relação; Jorge Mosset Iturraspe (1986, p. 245-246) e Patrice Jourdain (1992, p. 116), consideram danos à vida de relação os referentes ao prejuízo ao lazer, prejuízo sexual e prejuízo juvenil.
} 
subtração das possibilidades de sucesso em determinado processo aleatório no qual o sujeito esteja envolvido e para o qual já tenha orientado sua conduta, e por isso a chance perdida passa a compor a esfera de interesses legítimos do sujeito, que, atuando sob a premissa de realizar tudo o que norma não lhe proíbe, conduz sua ação para a consecução do resultado esperado. Nesses casos, quando a interrupção da álea se dá de maneira a prejudicar-lhe injustamente, ainda que não tenha sofrido violação de um direito subjetivo, o resultado danoso passa a ser relevante para o direito.

A despeito da ausência de previsão legal, como se procurará demonstrar, a jurisprudência do Superior Tribunal de Justiça tem admitido o ressarcimento dessa modalidade de dano o que, afirma-se, resulta justamente da compreensão de que o dano indenizável não mais se caracteriza como antigamente. A frustação do processo aleatório em que a parte está inserida, ainda que não caracterizada como direito subjetivo, tem o condão de conclamar a incidência do instituto da responsabilidade civil.

Por essa razão, antes da análise detida acerca dos arestos que traduzem as reflexões de provecta doutrina, necessário o compreender do conceito, do que efetivamente se entende por chance cuja perda ou frustração autoriza o ressarcimento.

\section{O EVOLVER HISTÓRICO E A CONCEITUAÇÃO NECESSÁRIA-A RESPONSABILIDADE CIVIL PELA PERDA DA CHANCE}

A mudança de paradigma da responsabilidade civil adveio do desenvolvimento da sociedade, alterando a atenção da doutrina com a transferência de foco da persecução da culpa do agente causador do dano, para o cabal ressarcimento da vítima. A superação do modelo liberal e o desenvolvimento acelerado das atividades econômico-industriais forçaram a objetivação da responsabilidade, baseando-se inclusive no risco criado por determinadas atividades.

Em verdade, o despontar de novos rumos no estudo da responsabilidade civil influencia e mesmo amplia o conceito de dano reparável. Desse modo, "fatos como quebras de expectativas ou confiança, quebra de privacidade, estresse emocional, risco econômico, perda de uma chance e perda de escolha já são considerados plenamente reparáveis" (SILVA, 2007, p. 6). 
Nos últimos cem anos, esclarece-se, a responsabilidade civil avançou no sentido de repudiar a reparação unicamente dos danos diretos e tangíveis e aponta para o conceito do dano reparável como forma de abarcar os danos intangíveis e determinadas expectativas. Por tratar de complexos conflitos originados dos fenômenos sociais ligados às probabilidades, o direito deve considerar as incertezas como integrante das soluções jurídicas (LEVIT, 1992, p. 138).

Nesse campo de probabilidades e possibilidades da vida social, em respeito ao princípio da reparação integral dos danos, igualmente como ocorreu com o dano moral, verifica-se o surgimento das chances perdidas como uma nova categoria de dano indenizável.

A teoria da responsabilidade civil pela perda da chance originou-se pelos esforços dos tribunais e doutrinadores franceses, conforme relatado por Geneviève Viney e Patrice Jourdain (1998, p. 74), referindo-se ao primeiro caso de aplicação, que remonta à data de 17 de julho de $1889^{3}$.

Por sua vez, no sistema do Common Law, o primeiro caso de que se tem notícia data de 1911, na Inglaterra, entre as partes Chaplin v. Hicks, no qual a autora era uma das 50 finalistas de um concurso de beleza e foi impedida pelo réu de realizar a aparição perante um júri (FISCHER, 1938, p. 608).

Partindo da França, a teoria encontrou terreno fértil para seu desenvolvimento na península itálica, com estudos iniciais desenvolvidos por Giovanni Pacchioni (1940, p. 109-115), quando em sua obra questiona acerca do que aconteceria nos casos em que alguém, por meio de uma conduta culposa, privasse outrem de uma possibilidade de lucro. $\mathrm{O}$ autor, entretanto, se posiciona contra a indenização pela chance perdida, pois, para ele, "una simplese possibilita, una chance, ha un certo valore sociale notevole, ma non um valore di mercato" (PACCHIONI, 1940, p. 111) ${ }^{4}$ Posição contrária apresentou Adriano De Cupis

\footnotetext{
3 Relatam as autoras que: “Ce mouvement, commencé à la fin du siècle dernier, n'a cessé de s'amplifier. L'exemple le plus ancien est fourni par un arrêt du 17 juillet 1889 qui a accepté d'indemniser la perte, provoquée par la faute d'un officier ministériel, de la possibilité de poursuivre une procédure et, par conséquent de gagner un procès. Or, depuis cet arrêt, la Cour de cassation a eu fréquemment l'occasion d'approuver des condamnations prononcées sur ce fondement, notamment contre des auxiliaires de justice (avocats ou avoués)". Tradução livre: Esse movimento, iniciado no fim do século passado, não parou de crescer. O exemplo mais antigo foi oferecido por um julgado de 17 de julho de 1889, que aceitou indenizar a perda, provocada pela culpa de um oficial ministerial, da possibilidade de seguir um procedimento e, por consequência, de ganhar um processo. Entretanto, depois deste julgado, a Corte de Cassação teve frequentemente a oportunidade de aprovar as condenações pronunciadas com esse fundamento, particularmente contra os auxiliares da justiça (advogados ou solicitadores).

${ }^{4}$ Na mesma esteira de pensamento: Francesco Donato Busnelli (1965, p. 46-52) não considera a possibilidade de reparação dessa categoria de danos por entender configurar-se a perda da chance como mero interesse de fato.
} 
(1966, p. 263-265), para quem existia um dano passível de reparação nos casos de perda da chance.

De fato, há quem considere De Cupis o responsável pela correta interpretação da teoria da perda da chance no direito italiano, por ter visualizado a chance perdida como dano independente do resultado final (SAVI, 2006, p. 10), embora não se possa olvidar a contribuição prestada por Maurizio Bocchiola (1976, p. 55-101), o qual levantou imprescindíveis e decisivas considerações quanto à prova do dano alegado e a classificação da chance perdida como lucro cessante ou dano emergente. Em que pese a construção doutrinária desses juristas, a Corte de Cassação italiana julgou o primeiro caso favorável à indenização pela perda da chance apenas em 19 de novembro de 1983 (SAVI, 2006, p. 25).

Em seu país-berço, a teoria foi mais utilizada na seara médica, conforme se extrai da passagem que trata das diversas manifestações jurisprudenciais em favor da indenização da perda da chance:

Cependant l'hypothèse qui a donné lieu aux applications lês plus nombreuses est incontestablement celle de la 'perte d'une chance de guérison ou de survie' qui a été admise á partir du milieu des années 1960 principalement à propos de la responsabilité des médecins et des établissements de soins (VINEY; JOURDAIN, 1998, p. 77) $)^{5}$.

A doutrina passa a aceitar a possibilidade de reparação de danos eventuais que seriam consequência do agente não ter cumprido com o convencionado ou de ter omitido informações para que o resultado esperado fosse positivo. Corroborando o exposto, em semelhante postura, entende-se:

Eso es lo que pasa, de modo especial, cuando el demandado ha privado, por su culpa, al demandante de una probabilidad de conseguir una ganancia o

\footnotetext{
5 Tradução livre: No entanto, a hipótese que deu origem a muitas aplicações, certamente foi o da 'perda de chance de cura ou sobrevivência', que foi admitida em meados dos anos de 1960, principalmente sobre a responsabilidade dos médicos e das instituições hospitalares. Miguel Kfouri Neto (2001, p. 4) informa que: "O primeiro julgado, na França, que inaugura a jurisprudência sobre a perda de uma chance, é da 1. ${ }^{a}$ Câmara da Corte de Cassação, reapreciando caso julgado pela Corte de Apelação de Paris, de 17/7/1964. O fato ocorreu em 1957. Houve um erro de diagnóstico, que redundou em tratamento inadequado. Entendeu-se em $1^{\mathrm{a}}$ instância que, entre o erro do médico e as graves consequências (invalidez) do menor não se podia estabelecer de modo preciso um nexo de causalidade. A Corte de Cassação assentou que: 'Presunções suficientemente graves, precisas e harmônicas podem conduzir à responsabilidade'. Tal entendimento foi acatado a partir da avaliação de o médico haver perdido uma 'chance' de agir de modo diverso e condenou-o a uma indenização de 65.000 francos".
} 
de evitar una perdida. La dificultad proviene de que, en este supuesto, no resulta posible ya esperar para determinar si el perjuicio existirá; la reparación del perjuicio no depende de acontecimientos futuros e inciertos. La situación es definitiva; nada la modificará ya; por su culpa, el demandado ha detenido el desarrollo de una serie de hechos que podían ser fuente de ganancias o de pérdidas. Eso es lo que expresa da Corte de Casación a decir que 'esté consumado el hecho del cual dependa el prejuicio eventual (MAZEUD; MAZEUD; TUNC, 1957, p. 307).

Nova postura se delineia, então, com base no entendimento de uma efetiva possibilidade de reparar uma chance perdida, ou seja, a oportunidade subtraída do lesado, mas dentro de um parâmetro, aquilo que o lesado poderia ter a possibilidade de perceber em seu favor, caso não houvesse a intervenção do agente causador do dano.

A adoção dessa teoria é um reflexo da conscientização de que o direito, como ciência social, por encontrar-se umbilicalmente ligado à sociedade, lida com situações imprevisíveis, como também o são as condutas humanas, devendo a ciência jurídica oferecer respostas para os problemas advindos dessa instabilidade.

Entretanto, em que pese a influência do direito francês na elaboração da codificação civil brasileira, não há, no ordenamento jurídico pátrio, regulamentação expressa sobre a responsabilidade civil pela perda da chance. O que se tem é o vanguardismo de alguns doutrinadores e juízes, aqueles desenvolvendo, a exemplo da doutrina estrangeira, as linhas gerais do instituto, e estes, aplicando a teoria aos casos concretos, buscando a efetivação da justiça a cada caso submetido a julgamento.

Desse modo, a indenização pela perda da chance deve ser interpretada e recepcionada, mesmo que ausente específico dispositivo legal regulamentando o tema. Isso justifica-se, devido à tendência da expansão dos danos reparáveis, encontráveis na leitura sistemática dos arts. 186 e 187, ao estabelecerem os contornos do ato ilícito; do art. 927, ao impor a obrigação de reparar o dano cometido; art. 948, ao prever também "outras formas de indenização" para o homicídio; do art. 949, ao estabelecer indenização também por outro tipo de prejuízo sofrido, no caso de lesão ou ofensa à saúde; e. por último, tendo em vista o art. 402, garantidor de uma completa indenização, por danos emergentes e lucros cessantes. 
Embora a realização da chance nunca seja certa, a perda da chance pode ser certa. Por estes motivos não vemos óbice à aplicação criteriosa da teoria. $\mathrm{O}$ que o art. 402 afasta é o dano meramente hipotético, mas se a vítima provar a adequação do nexo causal entre a ação culposa e ilícita do lesante e o dano sofrido (a perda da probabilidade séria e real), configurados estarão os pressupostos do dever de indenizar (MARTINS-COSTA, 2003, p. 362).

Não se encontra, pois, óbice à responsabilização pela perda da chance, frente ao desenvolvimento doutrinário do instituto da responsabilidade civil e pela intencional inexistência no código civil de enumeração taxativa dos danos indenizáveis, levando a decorrência lógica daquele, a intenção de que todo dano deve ser reparado.

A primeira menção à teoria da responsabilidade civil pela perda da chance na jurisprudência pátria remonta a 12 de junho de 1990, em acórdão proferido pelo Tribunal de Justiça do Rio Grande do Sul, com relatoria a cargo do Desembargador Ruy Rosado de Aguiar. Entendeu o magistrado não ser cabível no caso a aplicação dessa teoria, por considerar que, in concreto, na verdade existia uma relação de causalidade direta entre a conduta do réu e o dano suportado pela vítima, e não frustração de uma chance . $^{6}$.

Apesar da timidez tanto da doutrina quanto da jurisprudência, tem-se que a aceitação da doutrina da responsabilidade pela perda da chance, seja pelos doutrinadores clássicos como Caio Mário da Silva Pereira ou Aguiar Dias, seja pelos contemporâneos como Rafael Peteffi da Silva ou Judith Martins-Costa, é posição assente e os tribunais pátrios ${ }^{7}$, ainda que com

\footnotetext{
TJRS - Ap.Cível no. 589069996 - Rel: Des. Ruy Rosado de Aguiar - 5ª Câmara - j. 12/06/1990.

Muitos são os casos possíveis de se aplicar a teoria ora em comento, mas o Tribunal de Justiça do Rio Grande do Sul deu preciosa lição ao decidir: "Através de ato médico, permitiu ao paciente portador de pneumonia dupla, procurar a cura em tratamento domiciliar, quando se fazia ainda relevante sua permanência no hospital, resultando, desta atitude, a morte do paciente. Após uma cirurgia, o paciente foi liberado prematuramente e algum tempo depois, queixando-se de febre alta, foi orientado pelo médico a utilizar-se de antipirético. Com a saúde agravada, o paciente foi internado na Unidade de Terapia Intensiva, vindo a falecer". Segundo o relator Desembargador Araken de Assis: "Liberando o paciente e retardando seu reingresso na instituição hospitalar, o apelante fê-lo perder chance razoável de sobreviver, embora a virulência estatística da doença (TJRS - Ap. Cível no 596070979 - Rel.: Des. Araken de Assis - 5ª Câmara Cível - j. 15/06/1996). Assim, a não realização de exames, deixar de aplicar determinada terapia ou medicação, podem implicar no dever de indenizar em razão da razoável perda de uma chance que o paciente teve como o procedimento de seu médico e/ou hospital. É preciso deixar claro que no caso concreto, se o exame tivesse sido realizado ou a medicação tivesse sido ministrada, e estas medidas fossem insuficientes para evitar o dano, o dever de indenizar ainda persiste, pois que foi retirada do paciente a oportunidade, a chance de sobreviver ou de ter amenizado as consequências da doença, desde que esta chance fosse séria e razoável.
} 
passadas curtas e confusão de termos, têm procurado conceder reparação aos danos oriundos da perda de uma oportunidade, pelo que mostra-se importante o devido esclarecimento do próprio conceito de chance. Este, como dito, às vezes empregado de forma confusa e em situações não necessariamente ligadas a esse viés da responsabilidade civil.

E como decorrência natural da recepção da responsabilidade civil pela perda da chance, evidentemente surge necessidade de compreensão do respectivo conceito jurídico.

Observa-se nos ensinamentos de Ghersi (1997, p. 47-75) o atrelamento da certeza do dano à existência material e não conjectural de um impacto no patrimônio da pessoa. Destaca que dano revela uma crise no sistema de governabilidade e, embora nem todos os danos sejam reparáveis, nem tenham uma causa única, são resultados de diversas manifestações, da dialética entre o processo que está na essência mesmo do viver social, da busca pelo ser humano de equidade e igualdade. Bustamante Alsina (apud SANTOS, 1997, p. 21) faz acrescentar a ideia em semelhante direção:

A chance configura um dano atual, não hipotético. É ressarcível quando implica uma probabilidade suficiente de benefício econômico que resulta frustrado pelo responsável, e pode ser valorada em si mesma, prescindindo do resultado final incerto, em seu intrínseco valor econômico de probabilidade ${ }^{8}$.

Apesar do dano advindo da perda ser atual, a chance equivale a uma expectativa hipotética, materializada em um ganho ou dano final, vinculados ao sucesso do processo aleatório. Assim, se esse processo aleatório é interrompido por um ato imputável a determinado indivíduo, a vítima experimentará a perda de uma probabilidade de um evento favorável, sendo que esta pode ser estatisticamente calculada, a ponto de lhe ser conferido um caráter de certeza e, portanto, reconhecido como dano reparável (SILVA, 2007, p. 13).

Bocchiola (1976, p. 58) afirma que "o termo chance significa, em sentido jurídico, a probabilidade de obter um lucro ou evitar uma perda”. Prossegue o autor:

${ }^{8}$ Nesse sentido, Trigo Represas (2008, p.144): “[...] a chance es pues sustantiva en si misma, por cuanto la mera probabilidad de obtener una ganancia o ventaja comporta ya de por sí, implícitamente, un valor económico indiscutible". 
È inutile attendere per sapere se ci sara o no un preguidizio, percheè Il suo concretizzarsi non dipende affato da um quache avvenimento futuro ed incerto. La situazione è definitiva e non potrà essere modificata. Um determinato fatto há interroto Il corso normale degli eventi, che potevano dare origine ad una fonte di guadagno, in modo tale che non si è piu in grado di scoprire se la chance si sarebbe realizatta o meno (BOCCHIOLA, 1976, p. $59)^{9}$

Sem qualquer receio, em termos gerais, pode-se concluir que a reparação não corresponde à vantagem esperada, mas será quantificada economicamente com base na chance perdida.

Como essa teoria tem por escopo indenizar a vítima pela frustração em alcançar determinado objetivo, a responsabilidade surge em razão do comportamento do agente gerador da perda da chance, da oportunidade, ou seja, a expectativa de ganho que foi encerrada por sua conduta (GONDIN, 2005, p. 23).

Em relação ao tema da responsabilidade civil do médico, aponta-se que configurar-se-ia a perda da chance, "quando determinado acontecimento não ocorreu, mas poderia ter ocorrido, por si mesmo ou através de intervenção de terceiro. O evento teria sido possível, mas a atuação do médico tornou-o impossível, provocou a perda de uma chance" (FRADERA, 1992, p. 130) ${ }^{10}$.

O significado jurídico da perda da chance traduz-se na subtração de uma possibilidade, probabilidade ou esperança, e ainda de expectativas do indivíduo de auferir um lucro ou vantagem, como também de evitar a ocorrência de um evento danoso.

E, uma vez vencido o debate acerca da evolução e aceitação da teoria no ordenamento pátrio, firmado o conceito das chances indenizáveis, permite-se a análise de como o Superior Tribunal de Justiça tem considerado o instituto.

\footnotetext{
9 Tradução livre: É inútil esperar para saber se haverá ou não um prejuízo, porque o seu concretizar não depende absolutamente de qualquer acontecimento futuro e incerto. A situação é definitiva e não poderá ser modificada. Um determinado fato interrompeu o curso normal dos eventos que poderiam dar origem a uma fonte de lucro, de tal modo que não é mais possível descobrir se a chance teria ou não se realizado.

${ }^{10}$ François Chabas (1994, p. 934) afirma: "la pérdida de una chance se caracteriza por el alea intrínseca al perjuicio, lo que está en juego está afectado por una alea".
} 


\section{O QUE DIZ QUEM DIZ O DIREITO: O SUPERIOR TRIBUNAL DE JUSTIÇA E AS CHANCES PERDIDAS - (DES)CAMINHOS DE UMA COMPREENSÃO}

A teoria da responsabilidade civil pela perda da chance, como destacado, surgida no direito europeu e, com grande desenvolvimento no sistema do commom law norte-americano, refere-se à indenização do dano oriundo da frustração de uma possibilidade da qual desfrutava o agente inserido em um processo aleatório.

Ressalta-se que a jurisprudência americana recepciona com naturalidade o dano pela perda da chance na seara da responsabilidade civil médica, mas tem dificuldades em aceitá-la nos casos clássicos de responsabilidade civil. A doutrina francesa recepciona sem ressalvas a teoria da chance nos casos clássicos, o mesmo não ocorrendo na seara médica, amplamente aplicada pelos tribunais, mas controvertida doutrinariamente. Para Jean Pineau (1977, p. 115) não cabe a aplicação da teoria clássica da perda da chance na seara médica, em que as situações já se encontram definitivamente "cristalizadas", restando somente analisar o liame causal entre a conduta do agente e o dano final já concretizado. Afirma ainda: "classiquement, la notion de perte de chances concerne le préjudice; la notion de perte de chances de survie est relative, elle, à la causalité" 11 .

Desse modo, o estudo ora desenvolvido somente deter-se-á na análise dos casos clássicos de aplicação da teoria, ou seja, naqueles nos quais não se verifica o fim do processo aleatório, sendo impossível saber qual teria sido o resultado final, não esmiuçando questões referentes à perda da chance na seara médica ${ }^{12}$.

\footnotetext{
${ }^{11}$ Tradução livre: Classicamente, a noção de perda da chance se refere a prejuízo; a noção de perda da chance de sobrevivência é relativa à causalidade.

${ }^{12}$ Em referência à responsabilidade civil pela perda da chance na seara médica encontraram-se os seguintes julgados: REsp 1104665/RS, Rel. Ministro Massami Uyeda, Terceira Turma, julgado em 09/06/2009, no qual a aplicação da teoria foi afastada em decorrência da consideração de que havia mera possibilidade de evitar-se o resultado morte em caso do tratamento correto, não aplicando-se a teoria; AgRg no Ag 1222132/RS, Rel. Ministra Eliana Calmon, Segunda Turma, julgado em 03/12/ 2009 , na qual a teoria não foi profundamente analisada pelo tribunal em decorrência de questões processuais que impediram o seguimento do recurso especial; REsp 1184128/MS, Rel. Ministro Sidnei Beneti, Terceira Turma, julgado em 08/06/2010, sem maiores explanações em razão da vedação da reanálise de provas em sede de recurso especial; REsp 1254141/PR, Rel. Ministra Nancy Andrighi, Terceira Turma, julgado em 04/12/2012 e REsp 1335622/DF, Rel. Ministro Ricardo Villas Bôas Cueva, Terceira Turma, julgado em 18/12/2012, no qual, ao que parece houve uma má compreensão da teoria da perda da chance aplicada à responsabilidade médica. A ministra Nancy Andrighi divergiu do relator e apresentou voto mais condizente com a correta interpretação.
} 
Na experiência jurisprudencial brasileira, observam-se terem sido poucos os casos a tratar dessa modalidade de responsabilidade civil que alcançaram o Superior Tribunal de Justiça. Utilizando-se os vocábulos "perda" e "chance" para realizar a pesquisa no serviço disponibilizado no endereço eletrônico daquele tribunal, são apontados como resposta, em 08/10/2014, 41 acórdãos nos quais as ementas fazem referência à teoria. Analisando-se, entretanto, o inteiro teor das decisões, poucas são aquelas que efetivamente enfrentaram a teoria e desceram às minucias de enquadrar o dano pela perda da chance como patrimonial ou extrapatrimonial e proceder à devida quantificação do dano ${ }^{13}$.

A referência mais antiga é também bom exemplo de aplicação da teoria. Trata-se do Recurso Especial no ${ }^{\circ}$ 788.459/BA ${ }^{14}$, julgado em 08/11/2005. O caso ocorreu no programa de televisão denominado "Show do Milhão", um programa de perguntas e respostas, comandado por popular apresentador e veiculado no SBT, o qual oferecia um prêmio máximo de $\mathrm{R} \$ 1.000 .000,00$ (um milhão de

\footnotetext{
${ }^{13}$ Nos julgamentos do recursos REsp 1236809/DF, Rel. Ministro Sidnei Beneti, Terceira Turma, julgado em 22/05/2014; AgRg nos EREsp 1335622/DF, Rel. Ministro Antonio Carlos Ferreira, Segunda Seção, julgado em 12/03/2014; AgRg no AREsp 221.645/SP, Rel. Ministro Paulo De Tarso Sanseverino, Terceira Turma, julgado em 18/02/2014; AgRg no AREsp 81.821/RS, Rel. Ministro João Otávio De Noronha, Terceira Turma, julgado em 11/02/2014; REsp 1354100/TO, Rel. Ministra Eliana Calmon, Segunda Turma, julgado em 17/10/2013; REsp 1244685/SP, Rel. Ministro Luis Felipe Salomão, Quarta Turma, julgado em 03/10/2013; REsp 1383437/SP, Rel. Ministro Sidnei Beneti, Terceira Turma, julgado em 27/08/2013; AgRg no Ag 1106066/RS, Rel. Ministro Ricardo Villas Bôas Cueva, Terceira Turma, julgado em 07/05/2013; EDcl no REsp 1321606/MS, Rel. Ministro Antonio Carlos Ferreira, Quarta Turma, julgado em 23/04/2013; AgRg no REsp 1149718/MT, Rel. Ministro Antônio Carlos Ferreira, Quarta Turma, julgado em 21/02/2013; REsp 965.758/RS, Rel. Ministra Nancy Andrighi, Terceira Turma, julgado em 19/08/2008; AgRg no Ag 932.446/RS, Rel. Ministra Nancy Andrighi, Terceira Turma, julgado em 06/12/2007, há menção à teoria na ementa, mas sem desenvolvimento no corpo do acórdão, seja porque não caracterizado o dano nas instâncias ordinárias e, portanto, não ter sido viabilizada a reapreciação em sede de recurso especial, seja pelo não conhecimento do apelo em decorrência de outro motivo, que inviabilizou a análise do mérito. No caso do REsp 1197284/AM, Rel. Ministro Paulo de Tarso Sanseverino, Terceira Turma, julgado em 23/10/2012, há expressa menção no acórdão, mas sem aprofundamento. No REsp 1079185/MG, Rel. Ministra Nancy Andrighi, Terceira Turma, julgado em 11/11/2008, por sua vez, o Tribunal, ao tratar da responsabilidade civil do advogado, apesar de vislumbrar campo para a possível aplicação da teoria, no caso concreto, diante das conclusões fáticas firmadas pelo tribunal a quo, não restou configurada a chance efetivamente perdida, não sendo possível o recurso à tal teoria. A relatora deixou claro, entretanto, a compreensão de que, ao contrário do afirmado pelo tribunal de segunda instância, a perda da chance não pode somente ser uma "agregadora" do dano moral, mas ter contornos materiais bem definidos. Isso porque, em o tribunal estadual, reconhecendo a perda do prazo, considerou ter havido dano moral e concedeu a indenização no valor de $\mathrm{R} \$ 2.000,00$.

${ }^{14}$ Recurso Especial. Indenização. Impropriedade de pergunta formulada em programa de televisão. Perda da oportunidade. 1. O questionamento, em programa de perguntas e respostas, pela televisão, sem viabilidade lógica, uma vez que a Constituição Federal não indica percentual relativo às terras reservadas aos índios, acarreta, como decidido pelas instâncias ordinárias, a impossibilidade da prestação por culpa do devedor, impondo o dever de ressarcir o participante pelo que razoavelmente haja deixado de lucrar, pela perda da oportunidade. 2. Recurso conhecido e, em parte, provido (REsp n ${ }^{\circ}$ 788.459/BA, Rel. Ministro. Fernando Gonçalves, Quarta Turma, julgado em 08/11/ 2005).
} 
reais) em barras de ouro ao participante que respondesse corretamente a uma série de perguntas.

Observando-se os ditames estabelecidos pela emissora e produtora do programa, a cada pergunta respondida, o participante acumulava o montante a ser recebido ao final, galgando sempre rumo ao objetivo maior, a pergunta do tudo ou nada, que pagaria o valor de $\mathrm{R} \$ 1.000 .000,00$. Ocorre que, quando da última pergunta, já tendo acumulado $\mathrm{R} \$ 500.000,00$, o participante tinha de decidir entre responder ou não, arriscando tudo, caso errasse. Nesse caso, o apresentador do programa projeta na tela a última pergunta, a chamada "a pergunta do milhão". Após lê-la, o participante tem alguns segundos para optar por respondê-la ou parar. Optando por responder, caso o faça de maneira correta, o participante recebe outros $\mathrm{R} \$ 500.000,00$, completando um milhão de reais em prêmios. Por outro lado, errando, perde os $\mathrm{R} \$ 500.000,00$ acumulados ao longo de sua participação e recebendo apenas um prêmio simbólico de $\mathrm{R} \$ 300,00$. Optando por não responder a pergunta, o participante garante o prêmio acumulado de meio milhão de reais.

O dissenso teve lugar quando uma mulher, chegando à pergunta do milhão, viu-se obrigada a não arriscar, por entender que a pergunta, da forma em que fora formulada, não havia como ser respondida. Dessa forma, evitando a perda dos quinhentos mil reais que já havia acumulado, a autora optou por parar. Inconformada, entretanto, interpôs ação de indenização em face da organizadora do programa, vendo seu pedido julgado procedente quanto ao dano material em primeira instância, agraciada com o valor de $\mathrm{R} \$ 500.000,00$ a título de indenização.

O Tribunal de Justiça da Bahia negou provimento ao recurso da parte ré, mantendo a condenação no patamar lançado, o que foi desafiado por meio do recurso especial. De se fazer constar que, tanto o magistrado singular, quanto o colegiado do tribunal baiano haviam considerado o caso como lucros cessantes. O Superior Tribunal de Justiça considerou que, naquela situação, não havia meios de, em juízo de probabilidade, afirmar-se categoricamente que a autora responderia corretamente a pergunta final, de modo a ser impossível concluir, mesmo na esfera da probabilidade, que o normal andamento daquele processo aleatório conduziria ao acerto da questão. Por essa razão, faltaria pressuposto essencial para garantir a condenação ao pagamento da integralidade do valor que ganharia, se tivesse acertado a pergunta final, qual seja, a certeza do acréscimo patrimonial que caracterizaria o lucro cessante.

Por outro lado, por entender que houve um efetivo dano em face da pergunta formulada não possuir resposta, a Corte Superior reconheceu a perda 
da oportunidade e conferiu à requerente a indenização correspondente a $\mathrm{R} \$$ $125.000,00$, ou seja, a $1 \frac{1}{4}$ ou $25 \%$ do que a vítima receberia, se tivesse acertado a resposta, já que, diante da pergunta, ela teria tido quatro opções de resposta, tratando-se de simples probabilidade matemática.

Evidente pois, que, ao reformar o acórdão do tribunal baiano, afastando a condenação em R $\$ 500.000,00$, por entender ausentes os elementos caracterizadores do lucro cessante e, ao reconhecer a ressarcibilidade da chance perdida, o Superior Tribunal de Justiça enquadrou o dano pela perda da chance como dano emergente e, no caso, aplicou corretamente os critérios probabilísticos, pois, considerando o dano final, qual seja, a impossibilidade de auferir incremento patrimonial de meio milhão de reais, aplicou a probabilidade matemática evidente, diante da existência de quatro alternativas de resposta, alcançando, assim, justa indenização.

Em tempos mais recentes, a referida teoria foi mencionada no julgamento do Recurso Especial n ${ }^{\circ}$ 821.004/MG, de 16/11/2010, o qual, entretanto, apenas reafirma as bases fáticas de aplicação apontadas pelo tribunal a quo sem discorrer mais profundamente a respeito do assunto. Trata-se de responsabilização de uma rádio por divulgação de informações inverídicas acerca de um candidato a vereador nas vésperas da eleição, ocasião em que o candidato não foi eleito por uma diferença de 8 votos $^{15}$.

Por sua vez, no Recurso Especial nº. 1.190.180/RS, julgado em 16/11/ 2010, o relator menciona tratar-se o dano pela perda da chance de terceira modalidade entre o dano emergente e o lucro cessante. Nas suas palavras, "nesse cenário, a teoria da perda de uma chance (perte d'une chance) visa à responsabilização do agente causador não de um dano emergente, tampouco de lucros cessantes, mas de algo intermediário entre um e outro, precisamente a perda da possibilidade de se buscar posição mais vantajosa que muito provavelmente se alcançaria, não fosse o ato ilícito praticado". No caso concreto, afastou-se a aplicação da teoria pois o pedido autoral foi certo e determinado em relação aos danos que a parte autora suportara em decorrência da desídia do advogado réu. $\mathrm{O}$ autor, recorrido no recurso especial, não pleiteou na inicial a indenização por ter perdido a chance de se defender, mas pretendia a responsabilização do advogado por todo o prejuízo decorrente da improcedência da demanda. O tribunal a quo havia ajustado o pedido, reformando a sentença de primeiro grau para reduzir a indenização concedida e o fez com fundamento

${ }^{15}$ REsp 821.004/MG, Rel. Ministro Sidnei Beneti, Terceira Turma, julgado em 19/08/2010. 
na teoria da perda da chance, pelo que o Superior Tribunal de Justiça anulou a decisão por considera-la extra petita ${ }^{16}$.

Na controvérsia instaurada no AgRg no Resp 1.220.911/RS, julgado em 25/03/2011 ${ }^{17}$, entretanto, houve má compreensão da teoria ora em estudo. Isso porque o caso submetido a exame versava sobre a indenização pleiteada por um candidato em razão da sua eliminação na prova psicotécnica do concurso público para policial rodoviário federal. O recorrente sustenta sua pretensão na teoria da perda da chance, objetivando a indenização por danos materiais e morais em decorrência da perda da oportunidade de ser aprovado em concurso público.

O relator do caso considerou que não foi demonstrado pela parte a existência de chance real e séria de obter a vantagem almejada, asseverando não haver meios de aferir a probabilidade de aprovação do candidato e sua classificação dentro das trinta vagas previstas no edital "levando ainda em consideração o nível de dificuldade inerente aos concursos públicos e o número de candidatos inscritos". Para além de tais considerações, afirmou o relator que a teoria da perda da chance não sustenta a pretensão do recorrente, especialmente nos "casos em que o ato ilícito tira da vítima a oportunidade de obter uma situação futura melhor, como progredir na carreira artística ou no trabalho, arrumar um novo emprego", pois o recorrente já se encontrava aprovado em outro concurso, qual seja, para procurador da Advocacia Geral da União. Concluiu, assim, que, como o autor não pretendia a investidura no cargo, ainda que se reconhecesse a subtração da chance, não haveria dano a ser indenizado, vez que sem a posse e o exercício das atividades a ele inerentes, não havia falar-se em novo emprego ou progressão na carreira ou em benefício financeiro.

Com a devida vênia ao entendimento externado no julgado, há equívocos na compreensão da teoria. O relator equipara o dano pela perda da chance como modalidade intermediária entre o dano emergente e lucro cessante. Sob o caso em exame, trata-se, na verdade, de terreno clássico de aplicação da teoria.

Conforme consta do acórdão, a ilicitude do exame psicotécnico fora reconhecida pela sentença de primeiro grau e pelo acórdão do tribunal estadual. Dessa circunstância extrai-se que houve de fato um ato ilícito que pôs fim a um

${ }^{16}$ REsp 1190180/RS, Rel. Ministro Luis Felipe Salomão, Quarta Turma, julgado em 16/11/2010.

${ }^{17}$ AgRg no REsp 1220911/RS, Rel. Ministro Castro Meira, Segunda Turma, julgado em 17/03/2011. 
processo aleatório no qual o recorrente estava inserido na busca de uma vantagem. Nos termos anteriormente expostos, no momento de sua exclusão do certame, o recorrente suportou um dano injusto e, para sua caracterização, pouco importa que, em momento posterior, o resultado final que era perseguido no processo aleatório tenha deixado de lhe ser útil. $\mathrm{O}$ dano já havia sido caracterizado e consolidado em momento cronológico anterior. A afirmação de que o recorrente não assumiria o cargo, caso aprovado, e portanto, não seria possível falar em perda de "novo emprego" ou de progressão na carreira confundem o dano pela perda da chance com a vantagem final almejada com a conclusão do processo aleatório. A separação do dano final e da chance perdida é justamente o pressuposto para a aplicação da teoria pois, caso contrário, em momento algum se teria por caracterizada a chance perdida em razão da ausência de efetivo nexo entre a conduta do agente e a privação do resultado final, incerto em sua ocorrência.

Ademais, em tais condições, afirmar que não é possível calcular a probabilidade de sucesso do recorrente soa desarrazoado. Sabendo-se o número de vagas disponíveis e a quantidade de candidatos na disputa é possível extrair, sem quaisquer outras considerações que se fazem necessárias para a correta quantificação do dano pela perda da chance, uma probabilidade mínima de sucesso compartilhada por todos aqueles inseridos no certame.

O recorrente deixou claro que sua pretensão estava adstrita à reparação pela perda da chance de assunção ao cargo e não nos vencimentos não percebidos. O pedido foi adequado à pretensão deduzida. Muito embora no momento da propositura da ação a investidura no cargo não seja mais providência útil ao recorrente, tal fato não altera o passado no qual sua chance de continuar no certame foi injustamente eliminada. A aprovação do recorrente em outro concurso público em momento posterior apresenta-se, ainda, como indício de sua capacidade e deveria ter sido levada em conta no momento de apreciação de suas probabilidades de sucesso.

Ao que parece, portanto, houve equívoco entre o que se entende como o dano pela perda da chance como dano autônomo e o resultado final, e errônea compreensão para afastar a aplicação da teoria no caso em que, segundo se observa, trata-se de terreno propício para seu desenvolvimento.

Interessante análise advém do exame do Resp 1.210.732/SC, de relatoria do ministro Luis Felipe Salomão, julgado em 02/10/2012. Trata-se de indenização pleiteada por advogado em face da Empresa Brasileira de Correios e Telégrafos em decorrência de atraso na entrega de petição enviada por Sedex. O advogado 
enviou recurso pelo correio e, em decorrência do atraso na entrega, foi considerado intempestivo. Pleiteou danos morais e materiais correspondentes a $20 \%$ de honorários que receberia em caso de sucesso na demanda. O pedido foi julgado improcedente nas instâncias inferiores. O relator reconheceu o direito à indenização com base na teoria da perda da chance, mas negou os danos materiais sob o fundando de que "não há como acolher a pretensão, uma vez que não se mostra comprovada a ocorrência de nenhum dano", já que o sucesso em demanda semelhante não garantiria o sucesso daquela em que o recorrente perdera o prazo.

Muito embora o relator, tal como em outros julgados do Superior Tribunal de Justiça, considere a perda da chance como terceira modalidade de dano, diante das circunstâncias do caso concreto, não se poderia de fato responsabilizar a ECT da forma como requerida. Isso porque o dano cuja caracterização pretendeu o recorrente não corresponde à perda da chance de apreciação do recurso, mas à vantagem final que obteria em caso de sucesso da demanda. $\mathrm{O}$ pedido fora formulado de maneira equivocada quando o recorrente, por sua condição de advogado, pretende que seja reconhecido o seu direito a uma indenização por dano material, no percentual de $20 \%$, que receberia de seu cliente, a título de honorários advocatícios, se fosse vitoriosa a causa.

Entretanto, ao contrário do afirmado pelo ministro relator, há dano patrimonial a ser indenizado, correspondente justamente à chance de sucesso no recurso, o qual estava relacionado com interesses eminentemente patrimoniais. Ainda que o sucesso de demandas semelhantes não pudesse garantir o sucesso da ação na qual atuava o recorrente na qualidade de advogado, os altos índices de procedência indicam que a causa tinha probabilidades de se mostrar frutífera e, por consequência, o recorrente tinha probabilidade de auferir, ao final, os honorários contratuais. Essa chance, oportunidade, lhe foi retirada e, portanto, ensejaria a responsabilização com base na teoria da perda da chance, ainda que pequena fosse a probabilidade de sucesso.

Desse modo, a indenização poderia lhe ter sido negada não com base na não aplicação da teoria da perda da chance, mas em razão da formulação equivocada dos pedidos, o que condiciona a entrega da prestação jurisdicional aos seus exatos limites, sob pena de mácula do ato decisório.

Por outro lado, em oportunidade outra, andou bem o tribunal na aplicação da teoria. Trata-se do julgamento dos EDcl no AgRg no Ag 1.196.957/DF, de relatoria da Ministra Maria Isabel Galloti, julgado em 10/04/2012 ${ }^{18}$.

${ }^{18}$ EDcl no AgRg no Ag 1196957/DF, Rel. Ministra Maria Isabel Gallotti, Quarta Turma, julgado em $10 / 04 / 2012$. 
A questão de fundo envolve uma promoção de um supermercado cuja propaganda anunciava que "você concorre a 900 vales-compras de R\$100,00 e a 30 casas". A parte autora foi sorteada e quando da retirada do prêmio recebeu um vale-compra e a informação de que as casas seriam sorteadas entre os 900 ganhadores dos vale-compras. Entretanto, o segundo sorteio (das 30 casas) já havia ocorrido, sem a participação da autora, fato o qual a levou a buscar socorro junto ao Poder Judiciário por ter sido vítima de propaganda enganosa. Considerando-se ganhadora de um vale-compra e uma casa, protestou pelo refazimento do segundo sorteio ou a conversão em perdas e danos, correspondente ao pagamento do respectivo valor de uma das casas sorteadas, como também o reconhecimento da ocorrência de dano moral em razão da frustração causada pela publicidade enganosa.

O acórdão de segunda instância afastou a incidência do dano moral por não considerar ter ocorrido propaganda enganosa em razão das informações corretamente divulgadas tanto no bilhete quanto nos regulamentos existentes nas unidades do supermercado recorrido, bem como vedou a realização de novo sorteio por avaliar que a autora tinha uma mera expectativa de ser contemplada no sorteio no qual 900 pessoas concorreriam.

O Superior Tribunal de Justiça confirmou a inexistência de dano moral na hipótese mas, em relação às perdas e danos, deu interpretação distinta do tribunal a quo. Isso porque considerou que, sendo incontroverso o acordo acerca da participação dos 900 ganhadores dos vale-compras no sorteio das casas, ao não permitir que a parte autora dele participasse, o supermercado recorrido frustrou-lhe a chance de ser contemplada com uma casa. E essa frustração caracterizou a perda da chance indenizável.

A indenização foi fixada, então, em 1/30 do valor de uma casa (avaliada em $\mathrm{R} \$ 40.000,00)$, pois, nas palavras da relatora, "no caso presente, o dano consistiu não na perda do direito à casa, mas apenas na perda de trinta chances em novecentas de obter o direito ao prêmio".

Trata-se da exata compreensão da teoria como aqui se propõe. O tribunal considerou a chance como integrante do patrimônio da vítima, pois, no caso concreto, um compromisso contratual prévio estabelecera que todos os ganhadores dos vale-compras teriam direito a participar do segundo sorteio. Ao agir de forma negligente, não informando a parte autora, o supermercado recorrido privou-a da chance de participar do sorteio.

A vitória, absolutamente incerta, não permitiu se indenizasse a parte autora na integralidade do valor do prêmio. O resultado final, ou seja, o prêmio final 
almejado, serviu apenas de base para aplicação da fórmula matemática de cálculo probabilístico que representa as chances da autora de ganhar uma casa, concorrendo com outras 900 pessoas em 30 sorteios distintos.

Ainda que o acórdão não tenha expressamente mencionado, ao assim proceder, implica necessariamente no reconhecimento da chance como um dano certo e autônomo (independente) do resultado final. Ao indenizar as exatas probabilidades da recorrente, obedeceu-se ao disposto no art. 944 do Código Civil, medindo-se corretamente a indenização pela exata extensão do dano, que, por se tratar de um interesse patrimonial, configura-se no caso como um dano emergente.

No ano de 2013, a teoria se manteve presente nas decisões do Sodalício. Além dos julgados que fazem menção à teoria mas cujo mérito da questão não fora analisado ${ }^{19}$, encontra-se caso no qual afastou-se a aplicação da teoria pelo tribunal de origem por entender-se não ser caso de sua utilização. Veja-se o exemplo do Recurso Especial n ${ }^{\circ}$. 1.308.719/ $\mathrm{MG}^{20}$ : o Tribunal de Justiça de Minas Gerais havia concedido indenização com fundamento na teoria da perda da chance a uma servidora obrigada erroneamente a exonerar-se de um dos cargos ocupados em razão de suposta incompatibilidade (que se provou inexistente). Para o juízo a quo, a servidora perdera a chance de continuar a exercer seu cargo. O pedido indenizatório correspondia aos valores não recebidos em decorrência de ter sido a parte obrigada a exonerar-se do cargo que ocupava, acrescido das verbas remuneratórias e dos valores referentes à aposentadoria que teria direito. $\mathrm{O}$ tribunal estadual, entretanto, considerou não haver certeza de que a parte se manteria no cargo, logo não se poderia falar em lucros cessantes, mas apenas no ressarcimento da chance perdida, tendo fixado a indenização no valor de $\mathrm{R} \$ 100.000,00$ para cada uma das autoras.

O Superior Tribunal de Justiça, a seu turno, considerou, acertadamente, não ser caso de perda da chance, mas de lucro cessantes. Deve-se anotar não haver no julgado expressa menção à caracterização do dano patrimonial ocorrido como sendo lucro cessante; constata-se apenas a referência ao fato de que os autos deveriam retornar à origem para a apuração do dano de acordo com o art. 944, do Código Civil. Entretanto, diante das considerações lançadas pelo Relator, no sentido de que os recorrentes já exerciam ambos os cargos de forma regular e foram obrigados a deixá-los, não existindo dúvidas em relação

19 Elencados na nota de rodapé 13 .

${ }^{20}$ REsp 1308719/MG, Rel. Ministro Mauro Campbell Marques, Segunda Turma, julgado em 25/06/ 2013. 
a tal fato, somente pode-se inferir estar se referindo à certeza e determinação do dano patrimonial correspondente ao que deixaram de lucrar.

Em verdade, não havia situação hipotética ou processo aleatório no qual a recorrente estivesse inserido. A conformação fática encontrava-se completamente delineada; os recorrentes exerciam regularmente dois cargos públicos e, por ato ilícito da administração, foram obrigados a exonerarem-se de um deles. Todas as consequências desse ato decorrentes são de responsabilidade da administração e são certas e determinadas. Admitindo-se razoavelmente a continuidade da situação, o que deixaram de auferir com a exoneração, configura-se no dano suportado pelos recorrentes; lucro cessante, portanto.

Em situações como essa, faz-se necessário esclarecer que a caracterização da responsabilidade civil pela perda da chance exige a probabilidade de ocorrência de um evento concreto, bem como que a parte autora já esteja inserida em um processo com potencialidade para culminar na obtenção da vantagem ou no afastamento de um prejuízo. Isso porque, em regra, todas as circunstâncias na vida de uma pessoa ou permanecem como estão em determinado espaço-tempo ou alteram-se. Impedir a continuidade (ou forçar a mudança) de determinado estado não significa subtrair as chances de que tal estado tivesse se prolongado (ou permanecido o mesmo), a menos que a delimitação espaço-temporal alterada caracterizasse-se, intrinsecamente, pela aleatoriedade.

No caso do Recurso Especial no. 1.308.719/MG, no momento do ato ilícito da administração, a recorrente não objetiva auferir qualquer vantagem ou evitar prejuízo; apenas desenvolvia regularmente suas atividades. A continuidade de uma situação não caracterizada pela aleatoriedade do seu resultado foi interrompida e essa interrupção causou um dano, que não pode ser identificado com a subtração de uma chance mas sim, diretamente, com o resultado subtraído ou tornado de impossível alcance.

Entre os mais recentes julgados, datando do ano de 2014, encontra-se o Recurso Especial no ${ }^{\circ}$ 1.291.247/RJ ${ }^{21}$, de relatoria do Ministro Paulo de Tarso de Sanseverino.

O caso apresentado trata-se de pedido de indenização formulado por um casal e por seu fillho em razão do não comparecimento da clínica contratada para a coleta de células-tronco do cordão umbilical. Em primeira instância o

${ }^{21}$ REsp 1291247/RJ, Rel. Ministro Paulo de Tarso Sanseverino, Terceira Turma, julgado em 19/08/ 2014. 
pedido dos pais foi julgado procedente, com a fixação de indenização por danos extrapatrimoniais em R \$ 15.000,00 para ambos; a indenização para a criança foi negada, sob a alegação de se tratar de dano hipotético.

A conclusão do Tribunal de Justiça estadual, ao dar parcial provimento ao recurso dos autores, aumentou a indenização (fixando-a em $\mathrm{R} \$ 15.000,00$ para cada um dos pais). Entretanto, manteve a improcedência do pedido em favor da criança por considerar que não há meios de o menor incapaz sofrer um dano extrapatrimonial na situação, além de asseverar não estar caracterizada a perda da chance pela ausência de probabilidade concreta da necessidade da utilização do material genético não coletado.

Em apreciação do recurso especial manejado pelos autores, o STJ entendeu que houve, para a criança, perda da chance de ter suas células embrionárias colhidas e armazenadas para, se preciso fosse, no futuro, utilizálas em tratamento de saúde. Para o Ministro relator, "entre o dano certo e o hipotético, existe uma nova categoria de prejuízos, que foi identificada pela doutrina e aceita pela jurisprudência a partir da teoria da perda de uma chance". Por isso, considerou que no caso concreto, apesar de se tratar de perda da chance, não havia como proceder à quantificação por meios matemáticos de cálculos probabilísticos, dada a natureza extrapatrimonial, fixando a indenização em $\mathrm{R} \$ 60.000,00$.

A afirmação do relator - segundo a qual a perda da chance se localiza entre o dano certo e hipotético -, como as linhas anteriores demonstraram, corresponde a uma errônea interpretação, mormente em razão de a certeza do dano repousar na subtração efetiva da possibilidade de obter a vantagem ou evitar o prejuízo. A hipoteticidade repousa no resultado final do processo aleatório, que jamais pode ser certo, caso em que se caracterizariam os danos emergentes, lucros cessantes ou danos extrapatrimoniais tais como comumente previstos na legislação e recepcionados pela jurisprudência, conforme a situação concreta.

Muito embora a afirmação inicial do Ministro esteja, segundo ora se defende, equivocada, nas linhas seguintes do voto o relator demonstra compreender que a certeza do dano repousa na existência certa da probabilidade frustrada.

Ainda assim, a conclusão de que o não comparecimento da empresa contratada para a coleta do material genético subtraiu a chance da criança se beneficiar, no futuro, de eventual tratamento que se fizesse necessário, não configura, nas linhas do que se tem exposto, uma chance perdida. 
A Ministra Nancy Andrighi discordou dessa conclusão, abrindo a divergência, seguida pelo Ministro Sidnei Beneti, aparentemente com razão. Destacou a Ministra a não existência, no caso sob análise, de um processo aleatório em curso, enfatizando que a criança não estava inserida em qualquer sequência imediata de acontecimentos que pudessem conduzi-la ou a obter uma vantagem, ou a evitar um prejuízo.

Para essa situação podem-se utilizar as mesmas considerações feitas em relação ao Recurso Especial $n^{\circ}$. 1.308.719, de linhas anteriores. A despeito de não se levantarem objeções à conclusão do julgamento, o fundamento adotado para a concessão de indenização deveria ter sido distinto da teoria da perda da chance. Talvez se pudesse ter dito somente restar caracterizado um dano extrapatrimonial, mas não a perda da chance.

Do exposto percebe-se que, nas situações nas quais o dano pela perda da chance é considerado dano emergente, a discussão da reparação está pautada na possibilidade de atingir o resultado final. Ao considerá-lo lucro cessante, ou nega-se a indenização ou, então, concede-se na integralidade do resultado final almejado, descaracterizando-se as bases sobre as quais a teoria da responsabilidade civil pela perda da chance é desenvolvida, qual seja, quando o dano consiste na frustração da possibilidade e não na possibilidade em si.

Em decorrência de constituir assunto ainda recente nos tribunais pátrios, percebe-se que no âmbito do Superior Tribunal de Justiça, como responsável pela unificação da jurisprudência infraconstitucional, há exemplos de acertos na interpretação e aplicação da teoria, observando-se, também, fazer-se necessário aprofundamento na discussão pois, por vezes, a má compreensão pode conduzir a situações nas quais a parte tenha efetivamente suportado um dano injusto mas que, por vicissitudes inerentes à aplicação da teoria à prática, permanece sem o devido ressarcimento.

\section{CONSIDERAÇÕES FINAIS}

A teoria da responsabilidade civil pela perda da chance assenta-se, tratando-se da vertente clássica, na expansão da categoria dos danos indenizáveis. A partir dessa perspectiva, apresenta-se possível o ressarcimento do dano proveniente da interrupção de um processo aleatório por meio do qual o sujeito buscava auferir um resultado positivo ou evitar a ocorrência de um negativo.

O processo aleatório no qual o indivíduo encontra-se inserido pode estar relacionado com a satisfação de interesses patrimoniais ou extrapatrimoniais, 
os quais, uma vez ocorrida a interrupção, são determinantes para a caracterização da natureza jurídica do dano pela perda da chance.

Tratando-se de interesses patrimoniais, o dano pela perda da chance traduz-se como dano patrimonial, autônomo em relação ao resultado final, que deve ser quantificado com base em um cálculo matemático probabilístico que tenha como parâmetro o resultado final almejado e a probabilidade do indivíduo lesado alcançá-lo.

A jurisprudência do Superior Tribunal de Justiça, até o momento, foi instada a se manifestar em poucas oportunidades a respeito do dano pela perda da chance. Em parcela dos resultados encontrados na pesquisa realizada constata-se que o tribunal tem se deparado com questões que invocam a teoria para tratar da responsabilidade civil do médico, situação particular que demanda diverso esforço cognitivo para a correta compreensão, não abarcado por este estudo.

Nesses casos, a controvérsia instaura-se centrada na causalidade, e não na consideração de nova modalidade de dano. Distinguem-se duas modalidades de aplicação da teoria e, na seara médica, a proposta prima por reflexões a partir de utilizações alternativas do nexo de causalidade, tais como a teoria da causalidade parcial, e não parte da admissão da expansão da categoria dos danos ressarcíveis, ora fixada como premissa da abordagem.

Nas situações clássicas de responsabilidade civil pela perda da chance observam-se grandes acertos, os quais ainda dividem espaço com compreensões aparentemente equivocadas da teoria.

Verificam-se, em verdade, situações nas quais não se admite a probabilidade de sucesso como passível de ressarcimento, ou seja, nega-se a própria autonomia do dano pela perda da chance, retirando-se a força de qualquer pretensão ao ressarcimento da frustação de uma probabilidade de sucesso ou de evitar o prejuízo.

Em oportunidades outras os julgadores confundiram o dano pela chance perdida com o resultado final não alcançado no processo aleatório, a vantagem final esperada pelo indivíduo. Essa compreensão aproxima o dano pela perda da chance do dano emergente, ou do lucro cessante, já bastante conhecidos, pautando o reconhecimento da ressarcibilidade do dano e, posteriormente, os pressupostos a serem seguidos para sua liquidação, na tradicional teoria da responsabilidade civil. Nessas circunstâncias, acaba-se por conceder o ressarcimento abrangendo a vantagem final, ao invés de realizar-se cálculo probabilístico intrínseco à própria natureza do dano pela perda da chance. 
Deve-se destacar, ainda, o entendimento de que o dano pela perda da chance seja mero agregador do dano moral - utilizando-se a terminologia dos julgados. Os casos nos quais prevaleceu esse entendimento demonstram outra questão em relação à qual também se faz necessária a definição: quais os critérios para definir a natureza patrimonial ou extrapatrimonial de um dano, e o que efetivamente se considera dano moral (dúvidas as quais não foram objeto deste estudo).

A assunção de regra como essa descaracterizaria a teoria e retiraria a probabilidade da essência da configuração e liquidação do dano. Ao considerarse a perda da chance exclusivamente como modalidade de dano moral, far-seia repousar no arbítrio do magistrado os critérios exclusivos de quantificação do dano.

No Superior Tribunal de Justiça, portanto, analisando-se os julgados mencionados alhures, não se encontra definição da aplicação da teoria. Há, pelo momento, um cenário de desencontro de compreensões teóricas e não se pode mencionar que, segundo o posicionamento daquela corte, haja uma posição consolidada que possa servir de orientação às instâncias inferiores.

Nessas circunstâncias, o debate acerca dessa nova modalidade de dano apresenta-se evidentemente necessário, a fim de evitarem-se que situações danosas efetivamente suportadas pelos indivíduos perpetuam-se sem o necessário e devido ressarcimento a restabelecer o equilíbrio das relações e situações jurídicas intersubjetivas.

\section{REFERÊNCIAS}

AMARAL, Ana Cláudia Corrêa Zuin Mattos do; PONA, Éverton Willian. Ampliando horizontes: a expansão da categoria dos danos ressarcíveis como garantia da sustentabilidade jurídico-social nas relações privadas. In: KEMPFER, Marlene; ESPOLADOR, Rita de Cássia Resquetti Tarifa (Orgs). Estudos em direito negocial e sustentabilidade. Curitiba: CRV, 2012. p. 9-42.

BIANCA, Massimo Cesare. Realità sociele ed effettività della norma obligazioni e contratti responsabillità. Milão: Ed. Giuffrè, 2002. v. 2, t. 2.

BOCCHIOLA, Maurizio. Perdita de uma chance e certezza del danno. Rivista Trimestale di Diritto e Procedura Civille, Milano, Anno 30, p. 60-97, 1976. 
BUSNELLI, Francesco Donato. Perdita di una chance e risarcimento del danno. In: FORO ITALIAN, 2., 1965, Roma. Annali... Roma: Società Editrice del Foro Italiano, 1965. v. 38, p. 46-52.

CHABAS, François. La pérdida de una chance en el derecho francés. Trad. Aída R. Kemelmajer de Carlucci. Buenos Aires: Jurisprudencia Argentina, 1994.

DE CUPIS, Adriano. Il Danno: teoria generale della responsabilità civile. 2. ed. Milano: Giuffrè, 1966. v. 2.

FISCHER, Hans Albrecht. A reparação dos danos no direito civil. Tradução: Antonio de Arruda Ferrer Correia. Coimbra: Armênio Amado Editor, 1938.

FRADERA, Vera Maria Jacob de. A responsabilidade civil dos médicos. AJURIS: Revista da Associação dos Juizes do Rio Grande do Sul, Porto Alegre, v. 55, 1992.

GHERSI, Carlos A. Teoría general de la reparación de daños. Buenos Aires: Ed. Ástrea, 1997.

GONDIN, Glenda Gonçalves. Responsabilidade civil: teoria da perda de uma chance. Revista dos Tribunais,São Paulo, ano 94, v. 840, p. 11-36, out/ 2005.

ITURRASPE, Jorge Mosset. Responsabilidad por daños: el daño moral. Buenos Aires: Ediar, 1986. t.4.

JOURDAIN, Patrice. Les príncipes de la responsabilité cvile. Paris: Dalloz, 1992.

KFOURI NETO, Miguel. Responsabilidade civil do médico. 4.ed. São Paulo: Revista dos Tribunais, 2001.

LE TORNEAU, Philippe. La responsabilité civile. Paris: PUF, 2003. 
LEVIT, Nancy. Ethereal Torts. George Washington Law Review, Washington, v. 61, p. 136-192, nov.1992.

MARTINS-COSTA, Judith. Comentários ao novo código civil: do inadimplemento das obrigações. Rio de Janeiro: Forense, 2003. v. 5, t. 2.

MAZEAUD, Henri; MAZEAUD, Léon; TUNC, André. Tratado teórico y prático de la responsabilidade civil delictual y contratual. Trad. Luis Alcalá-Zamora y Castilho. 5.ed. Buenos Aires: Ediciones Jurídicas EuropaAmérica, 1957. v. 1, t. 1.

MORAES, Maria Celina Bodin de. A constitucionalização do direito civil e seus efeitos sobre a responsabilidade civil. In. MORAES, Maria Celina Bodin de. Na medida da pessoa humana. Estudos de direitos civilconstitucional. Rio de Janeiro: Renovar, 2010. p. 317-342.

PACCHIONI, Giovanni. Diritto civile italiano. Parte seconda: Diritto delle obbligazioni: Delitti e Quasi Delitti. Padova: CEDAM, 1940. v. 4.

PERLINGIERI, Pietro. Perfis do direito civil: introdução ao direito civil constitucional. Trad. Maria Cristina de Cicco. Rio de Janeiro: Renovar, 2002 .

PENNEAU, Jean. La responsabilité médicale. Paris: Éditions Sirey, 1977.

PINEAU, Jean; OUELLETTE, Monique. Théorie de la responsabilité civile. 2.ed. Montréal: Thémis, 1980.

REPRESAS, Félix Alberto Trigo. Pérdida de chance. Buenos Aires:

Editorial Ástrea, 2008.

SANTOS, Antonio Jeová. Dano moral indenizável. São Paulo: Lejus, 1997.

SAVI, Sérgio. Responsabilidade civil pela perda de uma chance. São Paulo: Atlas, 2006. 
SILVA, Rafael Pettefi da. Responsabilidade civil pela perda de uma chance. São Paulo: Atlas, 2007.

VINEY, Geneviève; Patrice Jourdain. Traité de droit civil. 2. ed. Paris: Librairie Générale de Droit et de Jurisprudencie: Les conditions de la responsabilité civile, 1998.

Submetido em: 15/10/2014 Aprovado em: 23/11/2014

Como citar: AMARAL, Ana Cláudia Corrêa Zuin Mattos do; PONA, Everton Willian. A perda da chance na jurisprudência do Superior Tribuanl de Justiça - Os (Des)caminhos de uma compreensão teórica. Scientia Iuris, Londrina,v.18,n.2,p.93-123, dez.2014. DOI:10.5433/2178-8189.2014v18n2p93. 